\title{
Statistical investigation of a dehumidification system performance using Gaussian process regression
}

\author{
Yousef Golizadeh Akhlaghi ${ }^{a}$, Xudong Zhao ${ }^{\mathrm{a}, *}$, Samson Shittu ${ }^{\mathrm{a}}$, Ali Badiei ${ }^{\mathrm{a}}$, \\ Marco E.G.V. Cattaneo ${ }^{b}$, Xiaoli Ma ${ }^{a}$ \\ a School of the Engineering and Computer Science, University of Hull, Hull, HU6 7RX, United Kingdom \\ ${ }^{\mathrm{b}}$ Department of Clinical Research, University of Basel, 4001, Basel, Switzerland
}

\section{A R T I C L E I N F O}

\section{Article history:}

Received 10 June 2019

Revised 30 July 2019

Accepted 1 September 2019

Available online 2 September 2019

\section{Keywords:}

Gaussian process regression

Operating parameters

Performance parameters

Dehumidification

Regeneration

\begin{abstract}
A B S T R A C T
Swift performance assessment of dehumidification systems, in design stage and while operation of the system is of substantial importance for commercialization and wide implementation of this technology. This paper presents a novel statistical model, employing Gaussian Process Regression (GPR) to investigate performance of a solar/waste energy driven dehumidification/regeneration cycle with a solid adsorbent bed. The statistical model takes thousands of operating conditions derived from a numerical model to predict the performance of the system. This predictive tool directly correlates the main operating parameters with the performance parameters of the system. The operating parameters considered in this study are: temperature, relative humidity and flow rate of process air, temperature of regeneration air, length of the desiccant bed, solar radiation intensity and operating time, and the selected performance parameters are: moisture extraction efficiency for the dehumidification cycle and moisture removal efficiency for the regeneration cycle. The model is evaluated by three metrics, namely: root mean square error (RSME), mean absolute percentage error (MAPE), and coefficient of determination $\left(\mathrm{R}^{2}\right)$. The maximum RSME and MAPE for moisture extraction are only $0.045,0.21 \%$, and for moisture removal efficiencies are 0.082 and $0.39 \%$, respectively, while the $\mathrm{R}^{2}$ value is derived as 0.97 . The developed model is used to investigate the impact of four selected operating parameters on system performance. Additionally, the system performance is predicted for randomly generated operating conditions as well as warm and humid climates. The developed GPR model provides a swift and highly accurate predictive tool for design of the dehumidification systems and for commercialization of the investigated dehumidification systems.
\end{abstract}

(c) 2019 Elsevier B.V. All rights reserved.

\section{Introduction}

Air with a relative humidity $(\mathrm{RH})$ between $40 \%$ and $60 \%$ is the most convenient indoor air [1]. Due to high energy consumption and low COP [2-4] of conventional mechanical vapor compression refrigeration air conditioning systems [2], energy efficient desiccant cooling and air-conditioning systems have attracted more attention in past decades [3]. Numerous research has suggested that the desiccant cooling and air-conditioning systems with solid or liquid desiccants are the potential substitutes to electrically driven vapor compression cooling systems [4-6].

Desiccant systems have been investigated by a number of experimental and numerical studies. Through experimental studies, Chen et al. [7] presented a novel polymer hollow fiber liquid des-

Abbreviations: OA, osteoarthritis; GPR, Gaussian process regression; RMSE, Root mean square error; MAPE, Mean absolute percentage error.

* Corresponding author.

E-mail addresses: xudong.zhao@hull.ac.uk (X. Zhao), x.ma@hull.ac.uk (X. Ma). iccant dehumidification system with latent effectiveness of 0.25 0.43 and the sensible effectiveness of $0.31-0.52$. Cho et al. [8] conducted a series of experiments and found that the cross-flow liquid desiccant dehumidifier has stable dehumidification performance regardless of the variations in operating parameters, but the crossflow dehumidifier performance is effected by temperature and humid process air conditions. Bai et al. [9] experimentally investigated the performance of the membrane-based liquid desiccant dehumidification system with calcium chloride. The sensible, latent and total effectiveness in their study were recorded as 0.49 , 0.55 , and 0.53 , respectively. Yang et al. [10] studied a novel solar solid dehumidification and regeneration bed with three regeneration methods. The results showed that the combined regeneration methods i.e., simulated solar radiation regeneration, microwave regeneration, and combined regeneration of the microwave and simulated solar radiation had higher regeneration efficiencies.

Among the numerical studies, Su et al. [11] presented a twostage liquid-desiccant dehumidification system with $30.63 \%$ lower power consumption compared to the conventional systems. Park 


\begin{tabular}{|c|c|}
\hline \multicolumn{2}{|c|}{ Nomenclature } \\
\hline d & Humidity ratio ( $\mathrm{kg}$ water vapor $/ \mathrm{kg}$ of dry air) \\
\hline W & Water content, (kg adsorbate/kg adsorbent) \\
\hline$c_{\mathrm{p}}$ & Specific heat capacity, $\mathrm{kJ} / \mathrm{kg} \mathrm{K}$ \\
\hline A & Cross-sectional area, $\mathrm{m}^{2}$ \\
\hline $\mathrm{C}$ & Perimeter of air flow passage, $\mathrm{m}$ \\
\hline $\mathrm{T}$ & Temperature, ${ }^{\circ} \mathrm{C}$ \\
\hline RH & Relative humidity \\
\hline $\mathrm{u}$ & Air velocity, $(\mathrm{m} / \mathrm{s})$ \\
\hline$D_{s}$ & surface diffusivity, $\mathrm{m}^{2} / \mathrm{s}$ \\
\hline $\mathrm{D}_{0}$ & Ordinary diffusivity, $\mathrm{m}^{2} / \mathrm{s}$ \\
\hline$D_{G}$ & Gas phase diffusivity, $\mathrm{m}^{2} / \mathrm{s}$ \\
\hline $\mathrm{L}$ & Bed length, $\mathrm{m}$ \\
\hline $\mathrm{X}$ & Dependent variable \\
\hline K & Thermal conductivity, $\mathrm{W} / \mathrm{m} \mathrm{K}$ \\
\hline Sh & Sherwood number \\
\hline $\mathrm{K}_{\mathrm{y}}$ & Coefficient of mass convection, $\mathrm{kg} / \mathrm{m}^{2} \mathrm{~s}$ \\
\hline $\mathrm{y}$ & Independent variable \\
\hline $\mathrm{N}$ & Number of operating conditions \\
\hline $\mathrm{F}$ & Volume ratio \\
\hline I & Solar radiation intensity, $\mathrm{W} / \mathrm{m}^{2}$ \\
\hline $\mathrm{T}$ & Time, $s$ \\
\hline$t_{h}$ & Hourly operating time, hr \\
\hline $\mathrm{Nu}$ & Nusselt number \\
\hline $\mathrm{z}$ & Air flow direction \\
\hline \multicolumn{2}{|c|}{ Subscripts } \\
\hline A & Air \\
\hline $\mathrm{p}$ & Process air \\
\hline out & Outlet \\
\hline i & Initial \\
\hline in & Inlet \\
\hline $\mathrm{d}$ & Desiccant \\
\hline me & Moisture extraction \\
\hline $\mathrm{mr}$ & Moisture removal \\
\hline$r$ & Regeneration \\
\hline $\mathrm{v}$ & Vapor \\
\hline $\mathrm{t}$ & Training \\
\hline $\mathrm{d}$ & Desiccant \\
\hline \multicolumn{2}{|c|}{ Greek symbols } \\
\hline$\alpha$ & Heat transfer coefficient, $\mathrm{kW} / \mathrm{m}^{2} \mathrm{~K}$ \\
\hline$\rho$ & Density, $\mathrm{kg} / \mathrm{m}^{3}$ \\
\hline$\eta$ & Efficiency \\
\hline$\epsilon$ & Measurement error \\
\hline$\varepsilon$ & Porosity \\
\hline$\Theta$ & Length-scale \\
\hline$\beta$ & Model coefficient \\
\hline$\phi$ & Volume ratio of desiccant,\% \\
\hline$\sigma_{f}^{2}$ & Signal variance \\
\hline
\end{tabular}

et al. [12] compared a liquid desiccant and evaporative coolingassisted system to a single stage one and found that the primary energy consumption is $17.4 \%$ lower while thermal and primary coefficients are $41 \%$ and $20 \%$ higher in the liquid desiccant and evaporative cooling-assisted system. Guo et al. [13] performed a hybrid method combining the electrodialysis and thermal regeneration method for liquid desiccant dehumidification and found electrodialysis accounted for $85 \%$ of the total energy consumption of liquid desiccant regeneration. Song et al. [14] detected the hidden relationship between the heating and cooling sources and the air states. Ali et al. [15] simulated different components of a liquid desiccant based dehumidification system for greenhouse cultivation. The model is found out to be effective in removing the moisture created by the crops inside the greenhouse. Das and Jai [16] developed a model for liquid desiccant dehumidification applications in which the maximum deviations of $\pm 20 \%$ was observed.

Study of literature revealed that the current numerical and experimental data are limited to the narrow data scales. Such limitation obstructs implementation of solar/waste energy driven dehumidification/regeneration cycle in real-life scenarios where multiple parameters vary simultaneously. The substantially high cost of constructing the experimental rigs for testing and analysis of these systems brings up further obstacles in exploring the system. Numerical models are one alternative to experimental studies. However, despite being cost effective, numerical models often require extensive input parameters and complicated equations to be solved which are extremely time consuming.

Therefore, to overcome the above-mentioned issues, a number of studies have proposed statistical methods. The comparative summary of these literatures and their achievements are listed in Table 1.

Detailed investigation of the literature revealed a research gap in utilizing full capacities of statistical modeling to predict performance of dehumidification systems by considering the commercialization of the this technology. Lack of a swift, accurate and easily done predictive tool, which can directly correlate the main parameters of this technology and predict the efficiencies of the system based on main parameters only, was an essence need. This paper pioneers in bringing the Gaussian Process Regression (GPR), which has been applied to a wide range of fields [17-25], as a predictive tool to investigate the performance of a solar/waste energy driven dehumidification/regeneration cycle, as well as, to introduce a new application for GPR. This, to the authors' knowledge, is the first statistical modeling study that applies GPR to investigate the performance of dehumidification systems. The developed GPR model directly correlates the main operating parameters i.e. temperature, relative humidity and flow rate of process air, temperature of regeneration air, length of the desiccant bed, solar radiation intensity and operating time with performance parameters i.e. moisture extraction efficiency for the dehumidification cycle and moisture removal efficiency for the regeneration cycle.

In Section 2, solar/waste energy driven dehumidification/regeneration cycle, GPR methodology and dataset development are explained. Then the model results including verification and applications are given in Section 3. Eventually, the conclusion is presented in section 4 .

\section{Methods}

\subsection{Description of a dehumidification system}

Schematic of the solar/waste energy driven dehumidification/regeneration cycle to be investigated in this study is shown in Fig. 1. A desiccant bed is located inside a channel that is constructed by a porous and visible-light LiCl-Sillicon-Gels material [2]. The bed specifications such as its dimensions and material play a key role in performance of both dehumidification and regeneration cycles. In the dehumidification process, the humid air (also called as process air), flows inside the channel and passes through the bed. The moisture of the process air is absorbed by the absorbent material in the desiccant bed owing to the partial vapor pressure difference between the solid absorbent surface of the bed and the process air. By flowing the process air through the desiccant bed, the absorbent material will gradually reach its saturation state. The regeneration process starts to regenerate the saturated absorbent material for the next dehumidification cycle. During the regeneration process, either a high temperature regeneration air with a temperature more than $70{ }^{\circ} \mathrm{C}$ or a low temperature 
Table 1

Summary of related studies.

\begin{tabular}{|c|c|c|c|}
\hline Study & System & Method & Remarks \\
\hline Park et al. [26] & Liquid desiccant system & $\begin{array}{l}\text { Response Surface } \\
\text { Methodology (RSM) }\end{array}$ & $\begin{array}{l}\text { A model was derived based on the operating parameters that significantly } \\
\text { affected the dehumidification effectiveness. }\end{array}$ \\
\hline Ou et al. [27] & $\begin{array}{l}\text { Liquid desiccant cooling and } \\
\text { dehumidification system }\end{array}$ & $\begin{array}{l}\text { Effectiveness-NTU, } \\
\text { Levenberg-Marquardt } \\
\text { and unscented Kalman } \\
\text { filter algorithm }\end{array}$ & $\begin{array}{l}\text { Experimental tests on a pilot plant revealed that the model can accurately } \\
\text { predict the system performance under different operating conditions. }\end{array}$ \\
\hline $\begin{array}{l}\text { Gandhidasan } \\
\text { and Mohandes } \\
{[28]}\end{array}$ & $\begin{array}{l}\text { Liquid desiccant } \\
\text { dehumidification }\end{array}$ & $\begin{array}{l}\text { Artificial Neural Network } \\
\text { (ANN) }\end{array}$ & $\begin{array}{l}\text { This study showed that the ANN can be used as a predictive tool with a } \\
\text { reasonable degree of accuracy. }\end{array}$ \\
\hline Jani et al. [29] & Rotary desiccant dehumidifier & $\begin{array}{l}\text { Artificial Neural Network } \\
\text { (ANN) }\end{array}$ & $\begin{array}{l}\text { Performance predictions through ANN are compared with the experiments } \\
\text { and a close agreement is observed. }\end{array}$ \\
\hline Current study & $\begin{array}{l}\text { A solar/waste energy driven } \\
\text { dehumidification/regeneration } \\
\text { cycle with a solid adsorbent } \\
\text { bed }\end{array}$ & $\begin{array}{l}\text { Gaussian Process } \\
\text { Regression (GPR) }\end{array}$ & $\begin{array}{l}\text { The developed GPR model provides a swift and highly accurate predictive } \\
\text { tool for design of the dehumidification systems and for commercialization of } \\
\text { the investigated dehumidification systems. }\end{array}$ \\
\hline
\end{tabular}

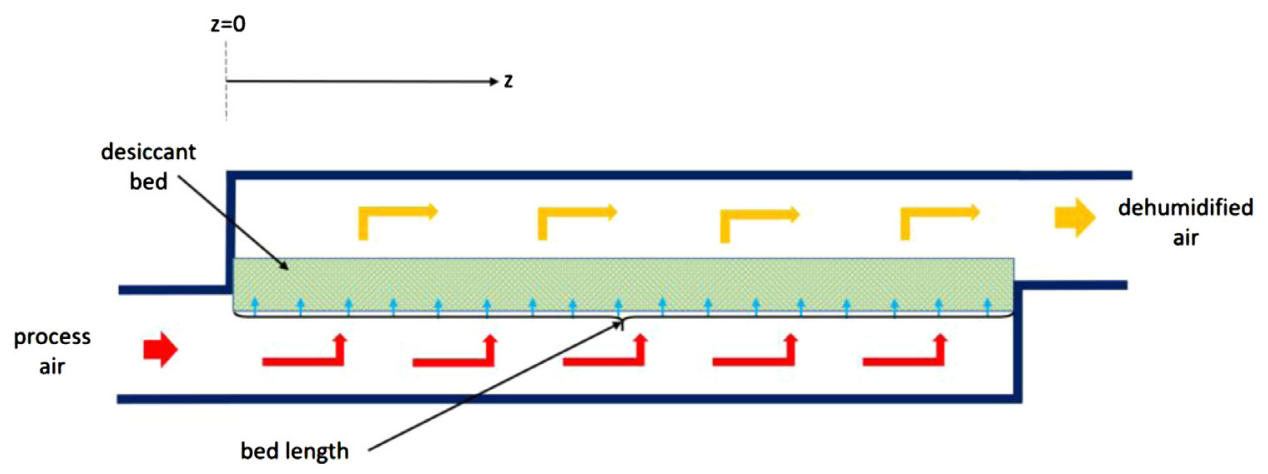

(a)

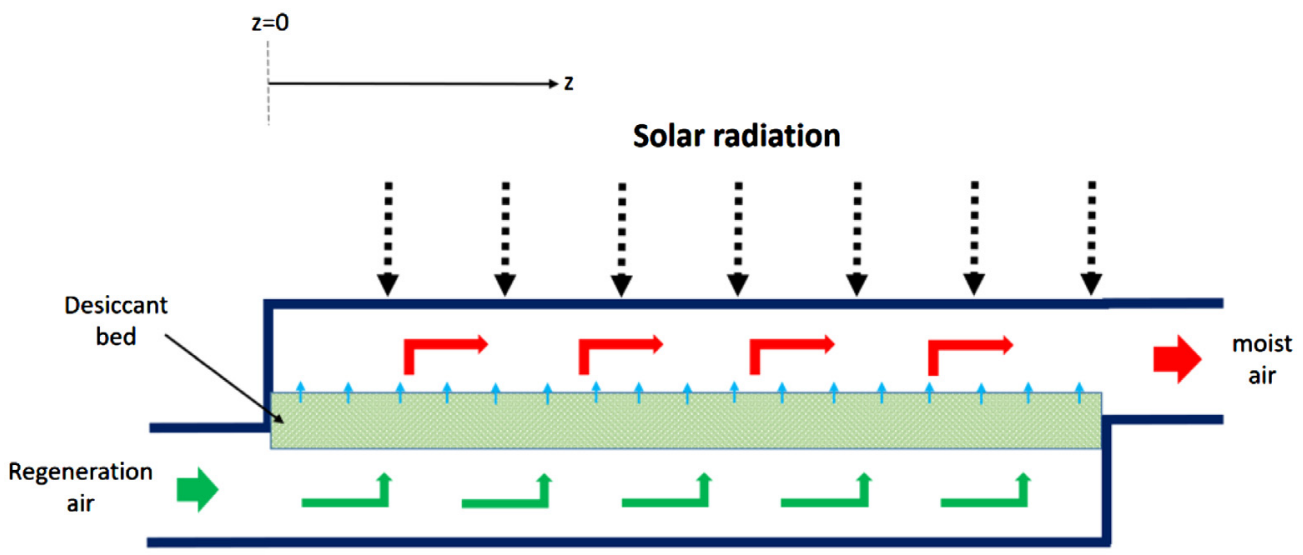

(b)

Fig. 1. Solar/waste energy driven dehumidification and regeneration cycle.

regeneration air heated with the solar radiation passes through the saturated absorbent. As the regeneration air passes through the channel, the heat is transferred from the regeneration air to the water inside the absorbent voids and evaporates water. Eventually, the regeneration air transports the evaporated water out of system and the regenerated absorbent is ready for another dehumidification cycle. When the solar radiation is not available, the regeneration air is initially heated by an available waste heat.

The system's performance is identified by two main parameters: moisture extraction efficiency and moisture removal efficiency. Moisture extraction efficiency is the ratio of difference in inlet and outlet moisture content of process air to inlet moisture content of process air [2]:

$\eta_{\mathrm{me}}=\frac{\mathrm{d}_{\mathrm{p}, \text { in }}-\mathrm{d}_{\mathrm{p}, \text { out }}}{\mathrm{d}_{\mathrm{p}, \text { in }}}$

where $d_{p}$ in is moisture content of inlet air and $d_{p}$, out is the moisture content of outlet air.

and the moisture removal efficiency for the regeneration cycle is ratio of difference in initial and final water content to initial water content of desiccant:

$\eta_{\mathrm{mr}}=\frac{\mathrm{W}_{i}-w}{\mathrm{~W}_{i}}$ 
where $W_{i}$ is initial water content of desiccant and $\mathrm{W}$ is the final water content of desiccant.

\subsection{Statistical model: Gaussian process regression}

Gaussian process regression (GPR) is a vigorous predictive tool which is capable of providing a predictive posterior distribution of outputs. This is a distinctive feature of GPR compared to the general regression models, such as linear or polynomial regressions which only estimate the value of the outputs. The GPR predicts the posterior probability distribution by a prior probability and then updates the prior probability distribution by training set. This means that the posterior distribution includes the full information of the prediction such as confidence level and prediction mean. A detailed description of the GPR has been presented in [30]. The main advantage of the Gaussian regression process is the way it defines the model. The GPR determines the structure of the covariance matrix of the independent variables as backbone of the model, while other regression techniques use the algebraic relationships of the independent and dependent variables [31].

For any training set as $\left\{D=\left(\mathrm{x}_{\mathrm{i}}, \mathrm{y}_{\mathrm{i}}\right) ; i=1,2,3, \ldots \mathrm{n}\right\}$ where $\mathrm{x}_{\mathrm{i}} \epsilon$ $\mathbb{R}^{\mathrm{d}}$ and $\mathrm{y}_{\mathrm{i}} \in \mathbb{R}$. The Gaussian process is a prior over a function, $\mathrm{f}$, based on the Bayesian theorem:

$\mathrm{p}(f \mid \mathrm{D})=\frac{p(f) p(D \mid f)}{p(D)}$

The general regression model is given as:

$y=x^{T} \beta+\varepsilon$

where $\beta$ is a regression coefficient calculated from the training data and $\varepsilon \sim \mathrm{N}\left(0, \sigma^{2}\right)$. The error variance $\sigma^{2}$ is also calculated using the training data. Simply for a Gaussian process with $\mathrm{n}$ observations, $\left\{\mathrm{x}_{\mathrm{i}} ; i=1,2,3, \ldots \mathrm{n}, \mathrm{x}_{\mathrm{i}} \in \mathbb{R}^{\mathrm{d}}\right\}$ and corresponding function variables, $\left\{f\left(x_{i}\right) ; i=1,2,3, \ldots n\right\}$, the joint (zero mean) Gaussian observation is:

$\mathrm{p}(f(x) \mid \mathrm{x})=N\left(0, \sigma^{2}\right)$

The Gaussian process describes the distribution over functions and it needs a covariance or kernel function and mean function to be fully specified.

$f(x) \sim G P\left(m(x), k\left(x, x^{\prime}\right)\right)$

The covariance function, defines the degree of correlation between the outputs of two input sets ( $\mathrm{x}$ and $x^{\prime}$ ), and is the backbone of the relationships between input variables. The mean covariance and the kernel functions can be defined as Eqs. (7) and 8, respectively:

$m(x)=E[f(x)]$

$$
\begin{aligned}
\operatorname{Cov}\left[f(x), f\left(x^{\prime}\right)\right] & =k\left(x, x^{\prime}\right) \\
& =E\left[(f(X)-m(x))\left(f\left(x^{\prime}\right)-m\left(x^{\prime}\right)\right)\right]
\end{aligned}
$$

Selection of the proper kernel function is important as estimation of the posterior distribution is significantly influenced by the prior distribution. An appropriate kernel is chosen on basis of the assumptions such as smoothness and likely patterns to be expected in the data. There are a number of different kernel functions such as: Matern, exponential, power-exponential, linear, intersection exist. In this study, one common kernel function, radial basis kernel function is used:

$k\left(x, x^{\prime}\right)=\sigma_{f}^{2} \exp \left[-\sum_{i=1}^{i=n} \frac{x(i)-x^{\prime}(i)^{2}}{2 \theta(i)^{2}}\right]$
Where $\sigma_{f}^{2}$ is the signal variance and $\theta$ is the length-scale. Once the prior kernel and mean functions are chosen, the GPR can be implemented to update the kernel and mean functions using the observed new dependent variable, $y^{\prime}$, for the given new independent variable, $x^{\prime}$, by a new function, $f^{\prime}$, to obtain the posterior estimation function as below:

$$
\begin{aligned}
& \mathrm{p}\left(\left[\begin{array}{l}
f \\
f^{\prime}
\end{array}\right]\right)=N\left(0,\left[\begin{array}{cc}
K(x, x)+\sigma^{2} \mathrm{I} & K\left(x, x^{\prime}\right) \\
K\left(x^{\prime}, x\right) & K\left(x^{\prime}, x^{\prime}\right)
\end{array}\right]\right) \\
& \mathrm{m}\left(f^{\prime}\right)=K\left(x^{\prime}, x\right)\left(K\left(x^{\prime}, x\right)+\sigma^{2} \mathrm{I}\right)^{-1} f \\
& \operatorname{Cov}\left[f^{\prime}\right]=K\left(x^{\prime}, x^{\prime}\right)-K\left(x^{\prime}, x\right)\left(K(x, x)+\sigma^{2} \mathrm{I}\right)^{-1} K\left(x, x^{\prime}\right)
\end{aligned}
$$

The posterior distribution is only Gaussian subject to the hyperparameters. It means that all of the kernel function parameters are assumed to be constant. In this study, the GPR analysis is carried out in $\mathrm{R}$ programing language 3.5.1 using the DiceKriging package. The detailed information about the DiceKriging package can be found in [32].

\subsection{Numerical model}

The numerical model used for data collection and GPR model testing, is based on energy and mass balance equations for two specified control volumes i.e.: flowing air and desiccant bed particles. A number of assumptions had to be made in order to simplify the calculations such as: the heat and mass transfer is a one dimensional; heat conduction in flow direction is ignored; heat and mass transfer coefficients between air and desiccant are assumed to be constant; the solar radiation in regeneration process is uniform; the heat and mass transfer coefficients between the air and the desiccant are constant and; any air state change at inlet and outlet of the system is ignored.

The dehumidification system operation is modelled by the following equations which are solved using finite element method in Matlab [2]. The mass balance for the flowing air stream is given as:

$\rho_{\mathrm{a}} \mathrm{fA}\left(\frac{\partial \mathrm{d}_{\mathrm{a}}}{\partial \mathrm{t}}+u \frac{\partial \mathrm{d}_{\mathrm{a}}}{\partial \mathrm{z}}\right)=\mathrm{K}_{\mathrm{y}} \mathrm{C}\left(\mathrm{d}_{\mathrm{d}}-\mathrm{d}_{\mathrm{a}}\right)$

where, $\rho_{\mathrm{a}}$ is density of the air, $\mathrm{f}$ is volume ratio of the air space to the whole channel, $\mathrm{A}$ is the Cross-sectional area of the channel, $d_{a}$ and $d_{d}$ are absolute humidity ratios of the air and desiccant respectively, $\mathrm{u}$ is flow rate, $\mathrm{K}_{\mathrm{y}}$ is Coefficient of mass convection, $\mathrm{C}$ is the perimeter of air flow passage, $t$ is time and $z$ indicates the flow direction.

The mass balance within the absorbent bed is given as:

$$
\begin{aligned}
\rho_{\mathrm{a}} \varepsilon(1 & -\mathrm{f}) \mathrm{A} \frac{\partial \mathrm{d}_{\mathrm{d}}}{\partial \mathrm{t}}+\rho_{\mathrm{d}}(1-\varepsilon)(1-\mathrm{f}) \mathrm{A} \phi \frac{\partial \mathrm{W}}{\partial \mathrm{t}} \\
& =\rho_{\mathrm{a}} \varepsilon(1-\mathrm{f}) \mathrm{A} \mathrm{D}_{\mathrm{G}} \frac{\partial^{2} \mathrm{~d}_{\mathrm{d}}}{\partial \mathrm{z}^{2}}+\rho_{\mathrm{d}} \varepsilon(1-\varepsilon)(1-\mathrm{f}) \mathrm{AD}_{\mathrm{s}} \frac{\partial^{2} \mathrm{~W}}{\partial \mathrm{z}^{2}} \\
& +\mathrm{K}_{\mathrm{y}} \mathrm{C}\left(\mathrm{d}_{\mathrm{a}}-\mathrm{d}_{\mathrm{d}}\right)
\end{aligned}
$$

where $\varepsilon$ is porosity, $\rho_{\mathrm{d}}$ is density of desiccant, $\phi$ is Volume ratio of desiccant, $\mathrm{W}$ is dry base water content, $\mathrm{D}_{\mathrm{G}}$ is gas phase diffusivity and $D_{s}$ is surface diffusivity.

The energy balance within the flowing air stream is given as:

$$
\begin{gathered}
\rho_{\mathrm{a}}\left(\mathrm{c}_{\mathrm{p}, \mathrm{a}}-\mathrm{d}_{\mathrm{a}} \mathrm{c}_{\mathrm{p}, \mathrm{v}}\right) \mathrm{fA}\left(\frac{\partial \mathrm{T}_{\mathrm{a}}}{\partial \mathrm{t}}+u \frac{\partial \mathrm{T}_{\mathrm{a}}}{\partial \mathrm{z}}\right)=\alpha \mathrm{C}\left(\mathrm{T}_{\mathrm{a}}-\mathrm{T}_{\mathrm{d}}\right) \\
+\mathrm{K}_{\mathrm{y}} \mathrm{c}_{\mathrm{p}, \mathrm{v}} \mathrm{C}\left(\mathrm{d}_{\mathrm{d}}-\mathrm{d}_{\mathrm{a}}\right)\left(\mathrm{T}_{\mathrm{a}}-\mathrm{T}_{\mathrm{d}}\right)
\end{gathered}
$$

where, $c_{p}$, a and $c_{p, v}$ are specific heat capacities of air and water vapor respectively, $\alpha$ is convective heat transfer coefficient, $T_{a}$ and $\mathrm{T}_{\mathrm{d}}$ are the temperature of the air and desiccant bed respectively. 
The energy balance within the absorbent bed is given as:

$$
\begin{aligned}
& \rho_{\mathrm{d}} \mathrm{c}_{\mathrm{p}, \mathrm{d}}(1-\mathrm{f}) \mathrm{A}(1-\varepsilon)\left(\frac{\partial \mathrm{T}_{\mathrm{d}}}{\partial \mathrm{t}}-\frac{\mathrm{k}_{\mathrm{d}}}{\mathrm{c}_{\mathrm{p}} \rho_{\mathrm{d}}} \frac{\partial^{2} \mathrm{~T}_{\mathrm{d}}}{\partial \mathrm{z}^{2}}\right) \\
&=\alpha \mathrm{C}\left(\mathrm{T}_{\mathrm{a}}-\mathrm{T}_{\mathrm{d}}\right)+\mathrm{K}_{\mathrm{y}} \mathrm{c}_{\mathrm{p}, \mathrm{v}} \mathrm{C}\left(\mathrm{d}_{\mathrm{d}}-\mathrm{d}_{\mathrm{a}}\right)\left(\mathrm{T}_{\mathrm{a}}-\mathrm{T}_{\mathrm{d}}\right) \\
& \quad+\mathrm{K}_{\mathrm{y}} \mathrm{C}\left(\mathrm{d}_{\mathrm{d}}-\mathrm{d}_{\mathrm{a}}\right) \mathrm{q}_{\mathrm{s}}+\mathrm{I} \cdot \mathrm{A} / \mathrm{l}
\end{aligned}
$$

Where, $c_{p, d}$ is specific heat capacity of desiccant bed, $k_{d}$ is thermal conductivity of desiccant, $\mathrm{I}$ is solar radiation intensity and 1 is the thickness of the absorbent bed.

The initial temperature of flowing air and desiccant are constant and identical to the initial temperature of inlet air and, the corresponding humidity ratios are also assumed to get the humidity ratio of the inlet air. The initial water content of desiccant is assumed to be $0.015[\mathrm{~kg} / \mathrm{kg}]$. The boundary temperature and humidity ratios at inlet for dehumidification and regeneration process are assumed constant for every time step. Moreover, the temperature and moisture content gradient at desiccant boundaries are zero.

The heat transfer coefficient is given as:

$\alpha=\frac{(\mathrm{Nu})(\mathrm{k})(\mathrm{C})}{4 \mathrm{~A}}$

Where $\mathrm{Nu}$ is nusselt number, $\mathrm{k}$ is thermal conductivity. The mass transfer coefficient is presented as:

$\mathrm{K}_{\mathrm{y}}=\rho_{\mathrm{a}} \frac{(\mathrm{Sh}) \mathrm{D}_{0} \mathrm{C}}{4 \mathrm{~A}}$

where $S h$ is Sherwood number and $D_{0}$ is Ordinary diffusivity.

\subsection{Model evaluation}

Three common metrics are used to evaluate the prediction accuracy of the GPR model: RMSE (root mean square error), MAPE (mean absolute percentage error) and $\mathrm{R}^{2}$ (coefficient of determination). Generally, RMSE measures deviation between the actual values and predicted values of the dependent variables, MAPE, is used to indicate the accuracy of the model for small changes in data and $\mathrm{R}^{2}$ is selected to measure the quality of the model by measuring the proportion of the total variations. These metrics are defined as:

RMSE $=\sqrt{\frac{1}{\mathrm{~N}} \sum_{i=1}^{\mathrm{N}}\left(\mathrm{y}_{\mathrm{i}}-\mathrm{y}_{\mathrm{p}_{\mathrm{i}}}\right)^{2}}$

MAPE $=\frac{1}{\mathrm{~N}}\left|\frac{\sum_{i=1}^{\mathrm{N}}\left(\mathrm{y}_{\mathrm{i}}-\mathrm{y}_{\mathrm{p}_{\mathrm{i}}}\right)}{\sum_{i=1}^{\mathrm{N}} \mathrm{y}_{\mathrm{i}}}\right| \times 100$

$\mathrm{R}^{2}=1-\frac{\sum_{i=1}^{\mathrm{N}}\left(\mathrm{y}_{\mathrm{i}}-\mathrm{y}_{\mathrm{p}_{\mathrm{i}}}\right)^{2}}{\sum_{i=1}^{\mathrm{N}}\left(\mathrm{y}_{\mathrm{i}}-\overline{\mathrm{y}}\right)^{2}}$

where $\mathrm{N}$ represents the number of observations, $\mathrm{y}_{\mathrm{i}}$ and $\mathrm{y}_{\mathrm{p}_{\mathrm{i}}}$ are the actual and predicted values of the dependent variables, and $\bar{y}$ is the mean value of the actual measured dependent variables in training set.

\subsection{Dataset development}

A comprehensive dataset comprising the selected key operating parameters, and corresponding performance parameters is generated using the numerical model. It is vital to mention that the operating parameters in current dehumidification system represent the input data for statistical model. In this study, seven main operating parameters (input data) and two performance parameters, based on a two-dimensional numerical and an experimental mod-
Table 2

Operating parameters and corresponding operation ranges.

\begin{tabular}{ll}
\hline Operating parameters & Ranges \\
\hline Temperature of the process air, ${ }^{\circ} \mathrm{C}$ & $25-40$ \\
Relative humidity of the both air, - & $0.6-0.9$ \\
Temperature of the regeneration air, ${ }^{\circ} \mathrm{C}$ & $70-80$ \\
Flow rate air stream, m/s & $1-4$ \\
Length of the desiccant bed, m & $1-5$ \\
Solar radiation intensity, $\mathrm{W} / \mathrm{m}^{2}$ & $0-1800$ \\
Operating time of each cycle, hr & $1-5$ \\
\hline
\end{tabular}

Table 3

Discrete values of operating parameters.

\begin{tabular}{lllllll}
\hline $\mathrm{T}_{\mathrm{p}}\left[{ }^{\circ} \mathrm{C}\right]$ & $\mathrm{RH}_{\mathrm{p}}[-]$ & $\mathrm{T}_{\mathrm{r}}\left[{ }^{\circ} \mathrm{C}\right]$ & $\mathrm{u}[\mathrm{m} / \mathrm{s}]$ & $\mathrm{L}_{\mathrm{d}}[\mathrm{m}]$ & $\mathrm{I}\left[\mathrm{W} / \mathrm{m}^{2}\right]$ & $\mathrm{t}_{\mathrm{h}}[\mathrm{hr}]$ \\
\hline 25 & 0.6 & 20 & 1 & 1 & 0 & 1 \\
27.5 & 0.678 & 70 & 1.5 & 2 & 600 & 2 \\
30 & 0.75 & 75 & 2 & 3 & 1200 & 3 \\
32.5 & 0.825 & 80 & 2.5 & 4 & 1800 & 4 \\
35 & 0.9 & 85 & 3 & 5 & & 5 \\
37.5 & & 90 & 3.5 & & & \\
40 & & & 4 & & & \\
\hline
\end{tabular}

els $[2,10]$, were selected. Temperature, relative humidity and flow rate of process air, temperature of regeneration air, length of the desiccant bed, solar radiation intensity and operating time are operating parameters; and moisture extraction efficiency as the performance factor of dehumidification process and moisture removal efficiency as the performance factor of regeneration process are the selected performance parameters. To concentrate the model on real operating conditions of the system, and to avoid unrealistic operating conditions, suitable ranges for each operating parameters are determined by a meticulous investigation of real operating conditions in numerical and experimental literatures as listed in Table 2 $[2,10]$. Flow rate and relative humidity of the air stream in both cycles are considered to be same [2].

The comprehensive dataset is divided into two parts: 1) training set, and 2) testing set. Training set is used to train and develop the model, and testing set is used to test the developed GPR model. Discrete values of operating parameters are needed to generate the comprehensive dataset. The values are randomly chosen to construct the datasets only, and validity of the model is not limited to these values. Having identified the discrete values, as listed in Table 3, all possible combinations of the discrete values are created to introduce all possible operating conditions of the system to the GPR model. Fig. 2 illustrates three operating conditions out of $n$ (6480) possible conditions in which 4320 are taken as training set and 2160 of them are specified as testing set. To build the dependent part of the datasets, performance parameters for each created operating conditions were calculated through the numerical model [2].

The flow diagram of the processes to develop the GPR model is shown in Fig. 3 and the detailed process steps are summarized as below:

I. Creation of operating conditions using the selected operating parameters (input data).

II. Generating the comprehensive dataset by the numerical model.

III. Classifying the comprehensive dataset into training and testing sets

IV. Training the GPR model employing the training set in R software package.

V. Testing the developed GPR model using the testing set.

VI. Model evaluations by RMSE, MAPE and $\mathrm{R}^{2}$ metrics.

VII. System performance prediction using the new inputs. 


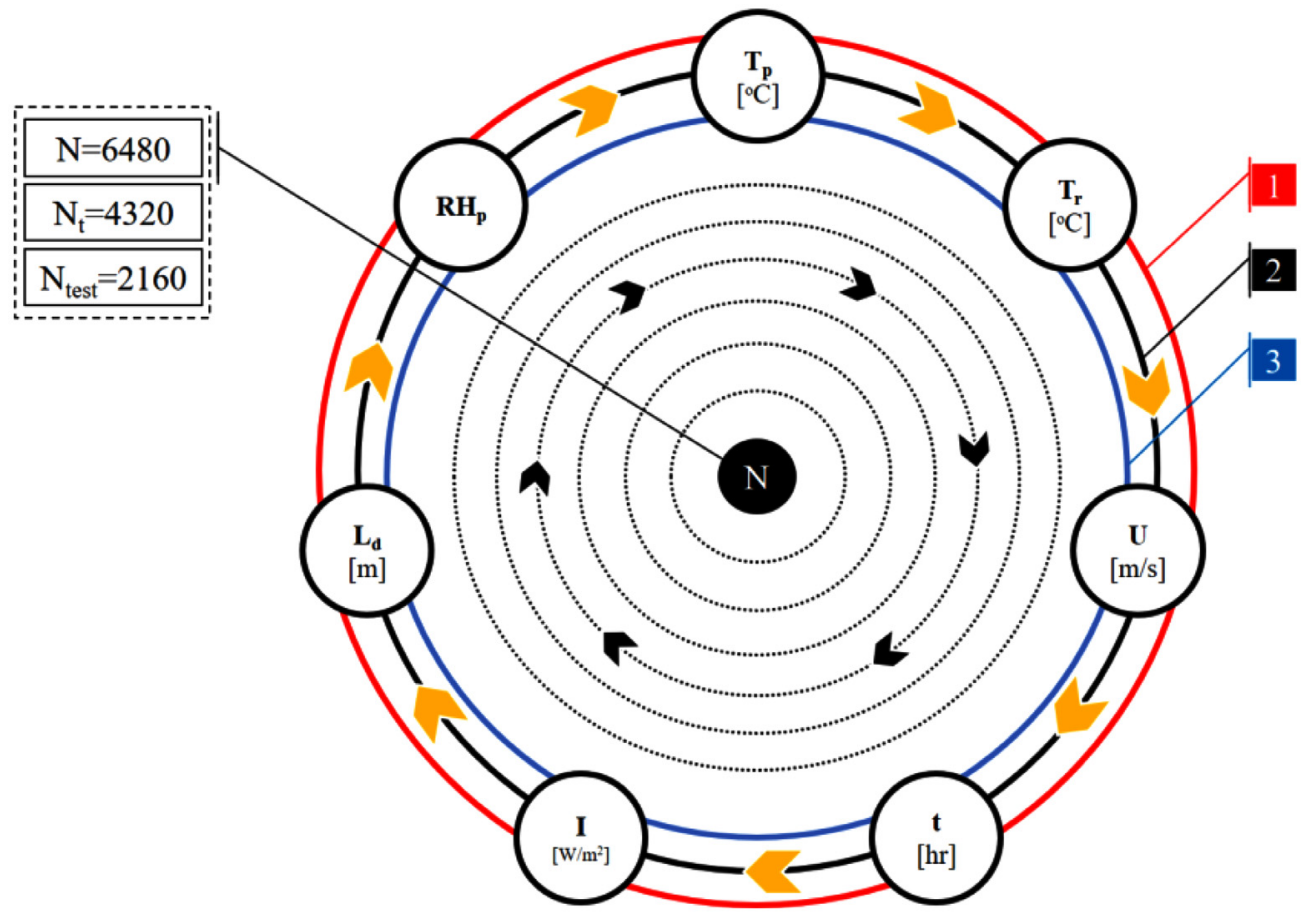

Fig. 2. Illustration of three operating conditions out of a total of $\mathrm{N}$ operating conditions.

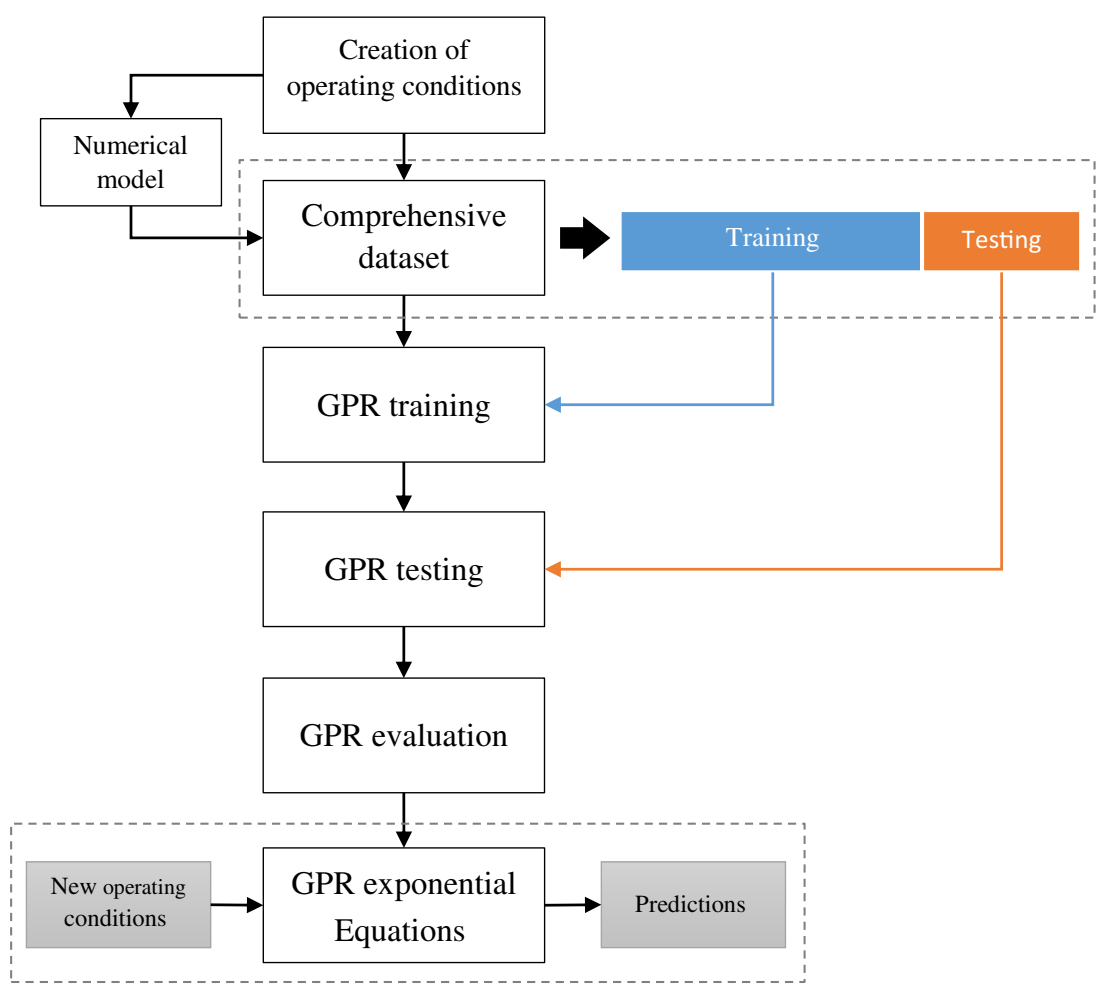

Fig. 3. Flow diagram of the GPR model development.

\section{Results and discussion}

This section presents the generated mathematical equation with corresponding coefficients for both dehumidification and regeneration processes. The model evaluation by specified metrics and model testing are also discussed. Finally, the three main applications of the produced GPR model are explained and investigated.

\subsection{Produced engineering equations}

The GPR model is presented in the form of an exponential equation for both dehumidification and regeneration cycles. The equation is purely constructed based on the selected operating parameters only, and is used to predict the moisture extraction and moisture removal efficiencies. The equation is 
Table 4

The coefficient and vector values of the GPR based model.

\begin{tabular}{|c|c|c|c|c|c|c|c|c|}
\hline \multirow[t]{2}{*}{$\mathrm{N}_{\mathrm{t}}$} & \multicolumn{4}{|c|}{ Dehumidification cycle } & \multicolumn{4}{|c|}{ Regeneration cycle } \\
\hline & $\bar{\alpha}$ & $\theta$ & $\mathrm{a}$ & $\mathrm{b}$ & $\bar{\alpha}$ & $\theta$ & $\mathrm{a}$ & $\mathrm{b}$ \\
\hline 1 & -4763.82 & 13.7 & 0.23 & 0.0024 & $-25,253.13$ & 19.4 & 0.91 & 0.003 \\
\hline 2 & 3456.32 & 0.6 & - & - & $47,221.24$ & 0.6 & - & - \\
\hline 3 & $-12,140.8$ & 2.36 & - & - & $-16,611.46$ & 4.78 & - & - \\
\hline 4 & -5001.25 & 3.61 & - & - & $12,841.15$ & $1.00 \mathrm{E}-10$ & - & - \\
\hline 5 & 2408.33 & 96.7 & - & - & $-15,837.75$ & 11.38 & - & - \\
\hline 6 & -6672.55 & 1319.62 & - & - & 8161.87 & 896.72 & - & - \\
\hline 7 & -2705.09 & 1.74 & & & 575.37 & 0.86 & & \\
\hline$\vdots$ & $\vdots$ & & - & - & $\vdots$ & - & - & - \\
\hline 4319 & 6695.32 & & - & - & 1325.65 & - & - & - \\
\hline 4320 & $-10,506$ & & - & - & 2624.53 & - & - & - \\
\hline
\end{tabular}

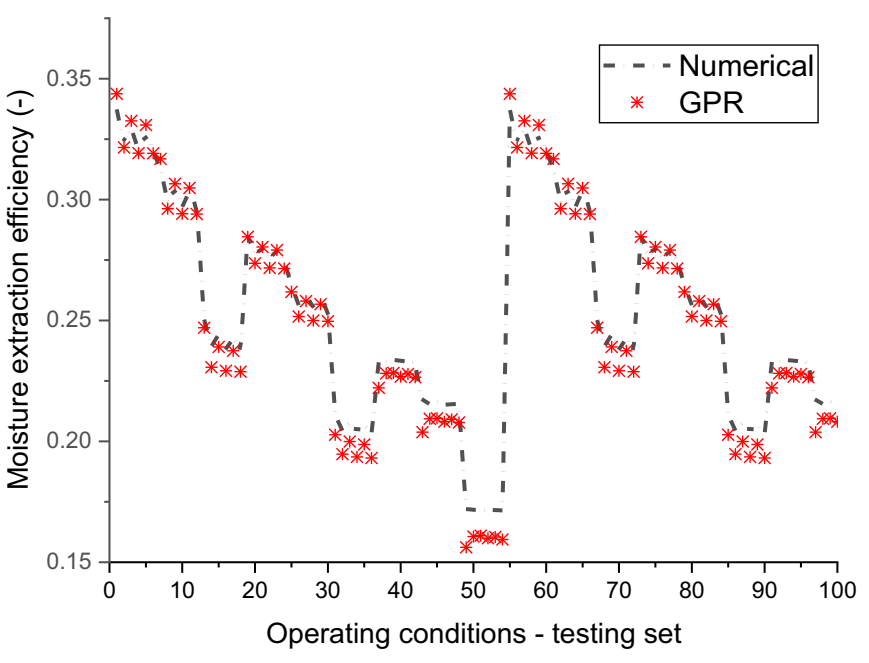

(a)

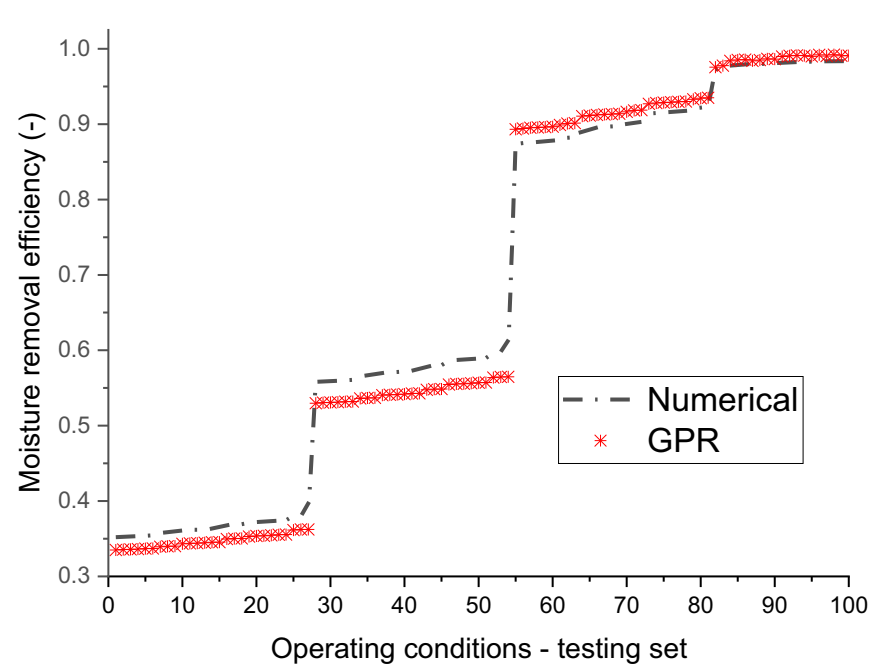

(b)

Fig. 4. Comparison of the GPR model and numerical model results based on testing set (a): moisture extraction efficiency comparison, (b): moisture removal efficiency comparison.

represented as:

$y=a+b * \sum_{i=1}^{\mathrm{N}_{t}} \alpha_{\mathrm{i}} \times \exp \beta(\mathrm{i})$

where a and $\mathrm{b}$ are constant coefficients, $\alpha$ is a vector specified in Table $3, \mathrm{~N}_{t}$ is the number of operating conditions in training set and y represents:

$y=\left\{\begin{array}{l}\eta_{\mathrm{me}}: \text { for dehumidification process } \# \\ \eta_{\mathrm{mr}}: \text { for regeneration process }\end{array}\right.$

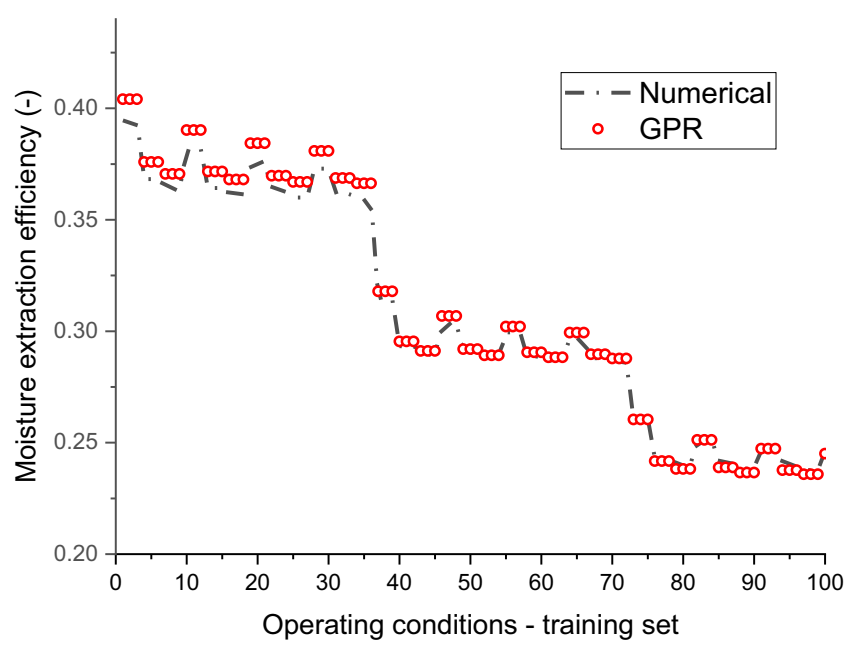

(a)

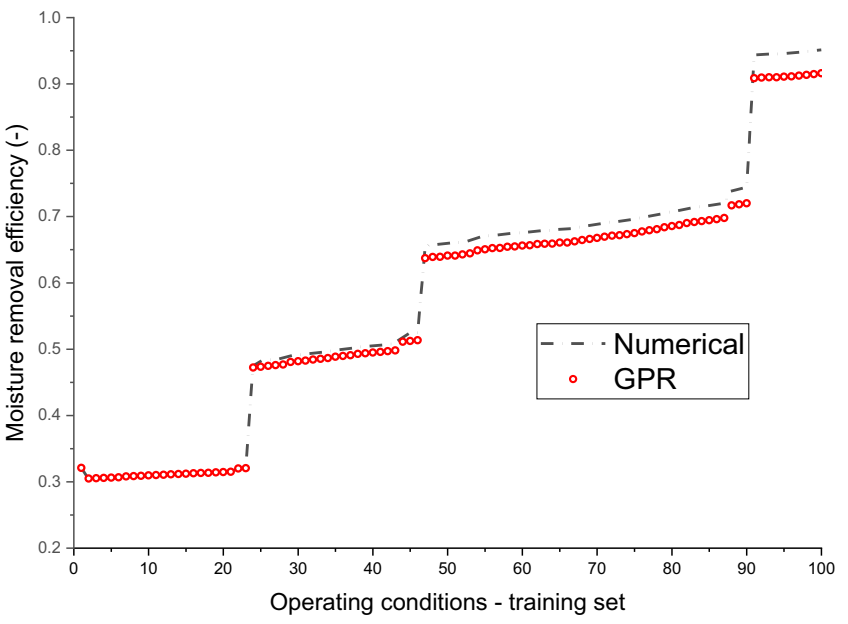

(b)

Fig. 5. Comparison of the GPR and numerical model results based on training set (a): moisture extraction efficiency, (b): moisture removal efficiency.

And the exponential power, $\beta$, is given in equation is calculated as:

$$
\begin{aligned}
\beta(\mathrm{i})= & \left(-\left(\mathrm{x}_{1}-\mathrm{T}_{\mathrm{p}}(\mathrm{i})^{2} /\left(2 \theta_{1}^{2}\right)\right)-\left(\mathrm{x}_{2}-\mathrm{RH}_{\mathrm{p}}(\mathrm{i})^{2} /\left(2 \theta_{2}^{2}\right)\right)\right. \\
& -\left(\mathrm{x}_{3}-\mathrm{u}(\mathrm{i})^{2} /\left(2 \theta_{3}^{2}\right)\right)-\left(\mathrm{x}_{4}-\mathrm{L}_{\mathrm{d}}(\mathrm{i})^{2} /\left(2 \theta_{4}^{2}\right)\right) \\
& -\left(\mathrm{x}_{5}-\mathrm{T}_{\mathrm{r}}(\mathrm{i})^{2} /\left(2 \theta_{5}^{2}\right)\right)-\left(\mathrm{x}_{6}-\mathrm{I}(\mathrm{i})^{2} /\left(2 \theta_{6}^{2}\right)\right) \\
& -\left(\mathrm{x}_{7}-t_{h}(\mathrm{i})^{2} /\left(2 \theta_{7}^{2}\right)\right)
\end{aligned}
$$

where, $\theta$ is a vector specified in Table 3 , and $\mathrm{x}_{1}, \mathrm{x}_{2}, \mathrm{x}_{3}, \mathrm{x}_{4}, \mathrm{x}_{5}, \mathrm{x}_{6}$ and $x_{7}$ represent any new operating parameters i.e., temperature, 
relative humidity and flow rate of the process air, length of the desiccant bed, temperature of the regeneration air and hourly operating time of the system, respectively. Table 4 gives all the coefficients and vector parameters for both dehumidification and regeneration cycles.

\subsection{Model testing}

The model testing is performed to test the developed GPR model. The predicted performance parameters from GPR model and from the numerical model [2] are compared. The comparison was performed under 2160 operating conditions in testing set. The comparison results are presented in Fig. 4 for first 100 operating conditions out of 2160 conditions. As it is seen in Fig. 4, there is a close agreement between the predicted performance parameters by GPR and the numerical model results. The testing set contributes to the generalization of the GPR model and indicates that the GPR model is adequately trained. This feature also indicated that the model is not restricted to the training set and thus simultaneously controlled the model overfitting and complexity. The comparison between numerical model and GPR predictions for

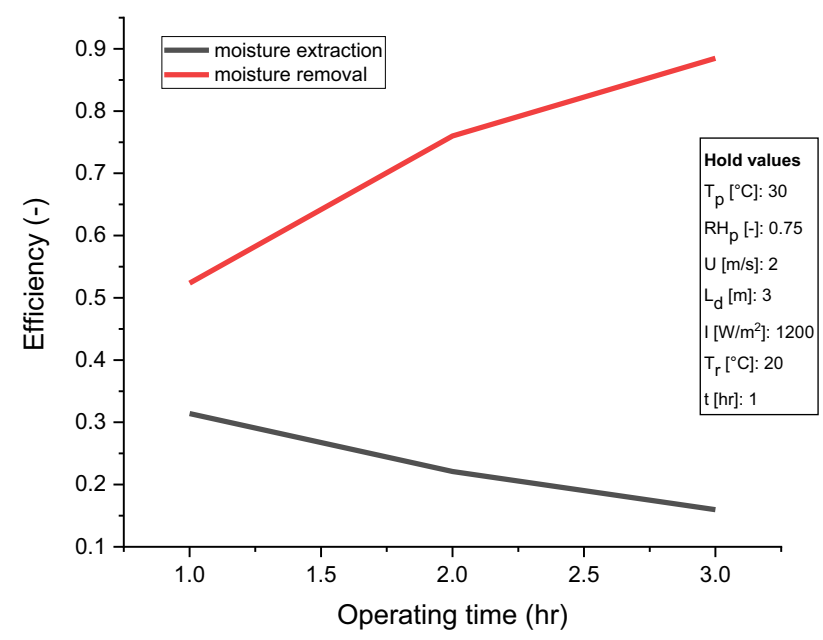

(a)

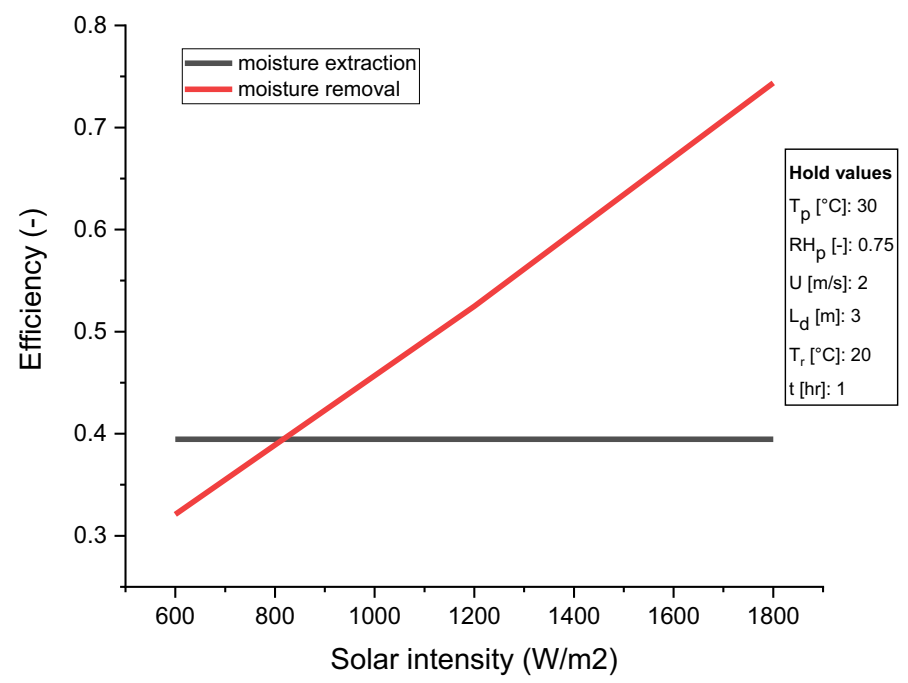

(c)
Table 5

Comparison of the metric values between the GPR and numerical model.

\begin{tabular}{llllllll}
\hline \multirow{2}{*}{ Set } & \multicolumn{2}{l}{ Moisture extraction efficiency } & & \multicolumn{2}{l}{ Moisture removal efficiency } \\
\cline { 2 - 3 } \cline { 7 - 8 } & RSME & MAPE & $\mathrm{R}^{2}$ & & RSME & MAPE & $\mathrm{R}^{2}$ \\
\hline Training & 0.012 & 0.11 & 1 & & 0.03 & 0.25 & 0.98 \\
Testing & 0.045 & 0.21 & 0.98 & & 0.082 & 0.39 & 0.97 \\
\hline
\end{tabular}

training set are also illustrated in Fig. 5 for the first 100 operating conditions out of 4320 conditions. The overall comparison results were evaluated by the selected metrics given in Table 5 . The maximum RSME and MAPE for moisture extraction were found to be 0.045 and 0.21 , and for moisture removal efficiencies to be 0.082 and 0.39 , respectively; and the lowest $R^{2}$ was recorded as 0.97 . The close agreement of results between the two models and also the very small error values proved the GPR model to be reliable and validated its results. Therefore, it can be concluded with high certainty that the model results are valid for any operating conditions constructed by the predefined ranges. Detailed comparison between different statistical approaches e.g., Artificial Neural Network (ANN), Support Vector Regression (SVR) and Kriging can be found in literatures [33,34].

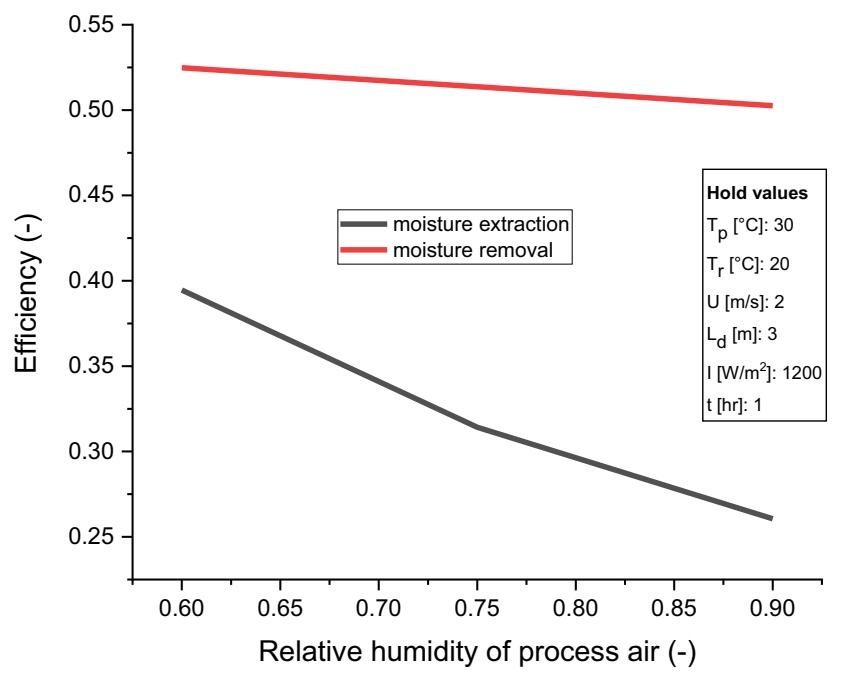

(b)

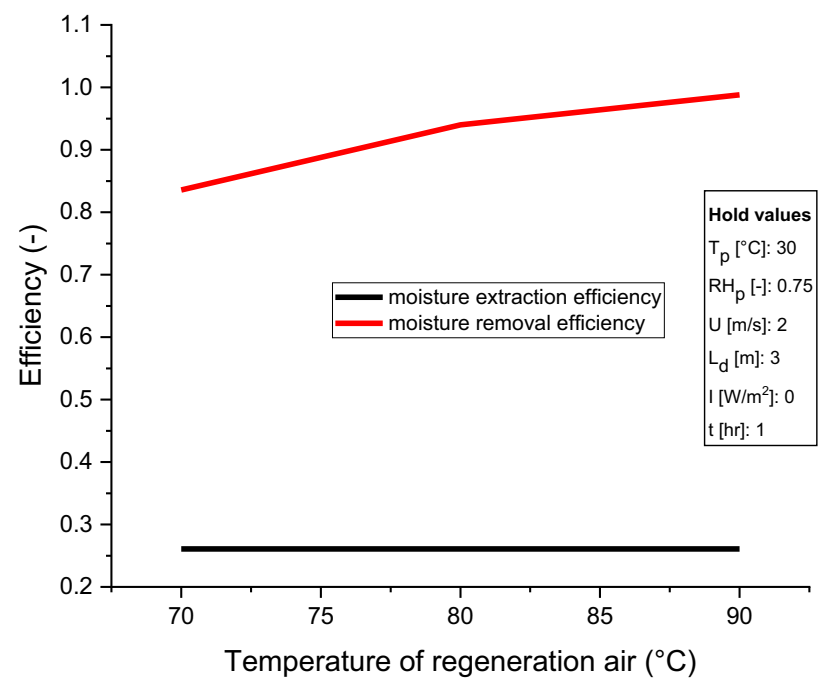

(d)

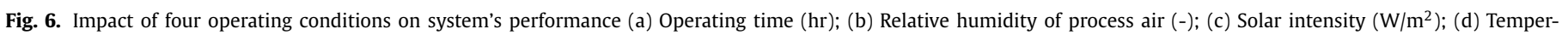
ature of regeneration $\operatorname{air}\left({ }^{\circ} \mathrm{C}\right)$. 


\subsection{Application of the GPR based model}

This section presents three main applications of the GPR model. The impact of four main parameters on the performance of solar/waste energy driven dehumidification/regeneration cycle are analysed and discussed to demonstrate the model capability in investigating the effect of different parameters. Additionally, the moisture extraction and moisture removal efficiencies of the system are predicted for a number of randomly generated operating conditions to prove model's applicability in any random operating conditions. Eventually, the system's performance is predicted in two warm and humid climates to show the applicability of the model in real conditions.

\subsubsection{Impact of the operating parameters on system's performance}

Effect of four selected operating parameters, namely: hourly operating time, relative humidity of the process air, solar intensity and temperature of regeneration air on performance of the system are shown in Fig. 6. In analysis of system performance based on specified operating parameters, other operating parameters were held constant to observe the impact of the selected parameters only.

To study the effect of operation time, the performance of the system was predicted in three hours of the operation. As can be seen in Fig. 6(a), moisture extraction efficiency decreases from 0.31 to 0.15 as time of operation increases. This is due to the fact that an increase in operation time leads to more saturated desiccant bed which leads to less heat and mass transfer from process air to the desiccant bed. Contrarily, the moisture removal efficiency increases over the same period. This is simply because an increase in operation time contributes to more water evaporation from the saturated desiccant bed. However, a slight decrease in slope of the moisture removal efficiency is visible as the regeneration cycle eventually reaches the steady state.

It can be observed in Fig. 6(b) that both moisture extraction and moisture removal efficiencies decrease when relative humidity of the process air is increased from $60 \%$ to $90 \%$. However, this trend is more visible in the dehumidification cycle. This was expected as the performance of the dehumidification cycle is highly dependent on humidity of the process air. The operating time in this case was

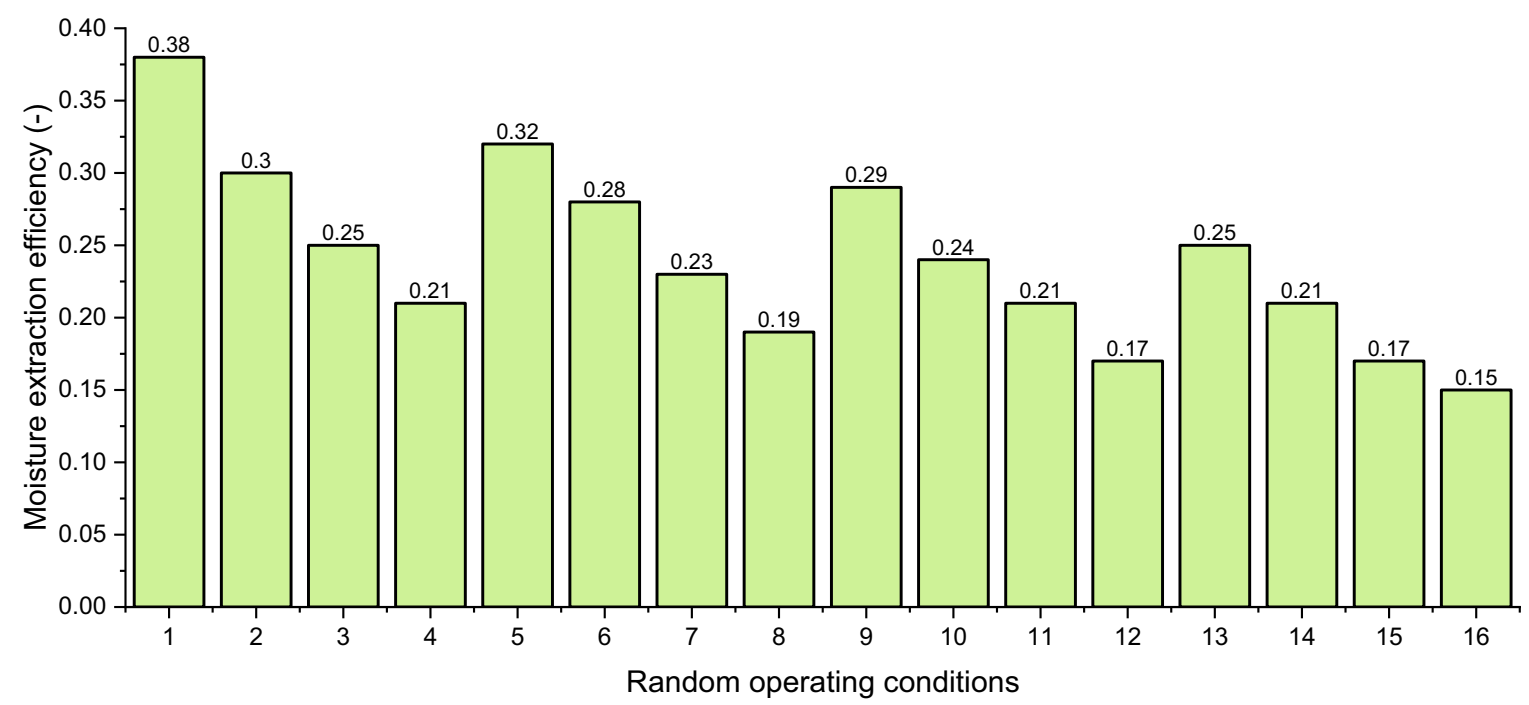

(a)

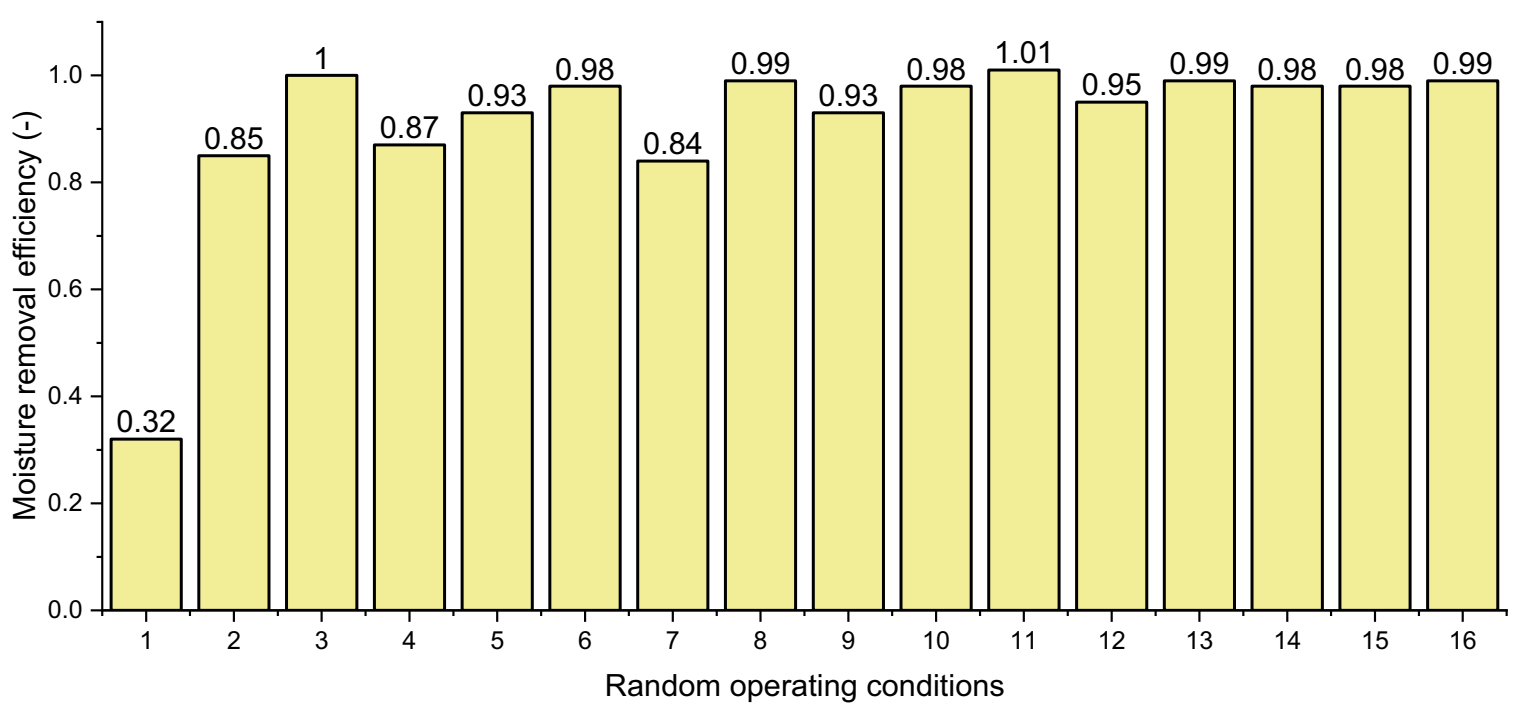

(b)

Fig. 7. Prediction of the system performance under randomly generated operating conditions; (a): moisture extraction efficiency; (b): moisture removal efficiency. 


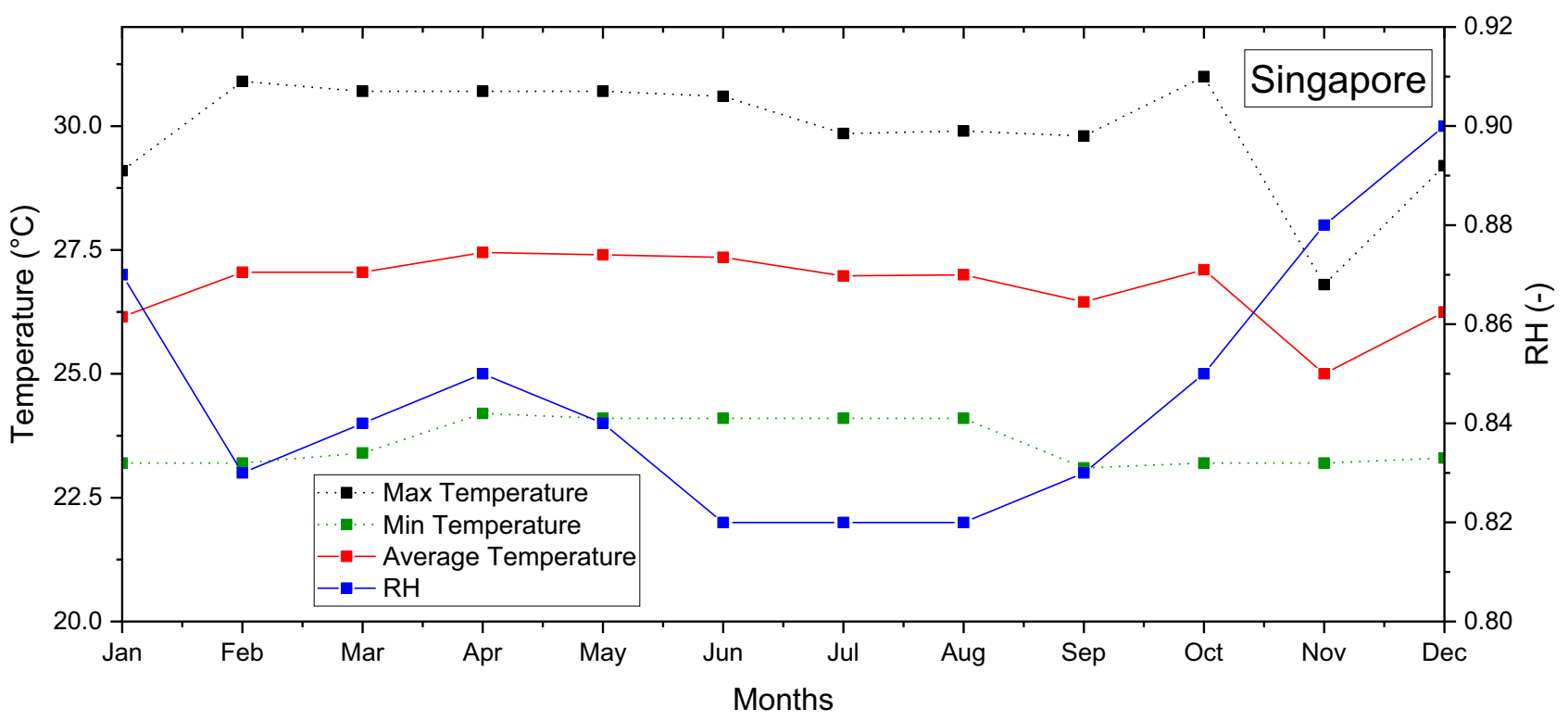

(a)

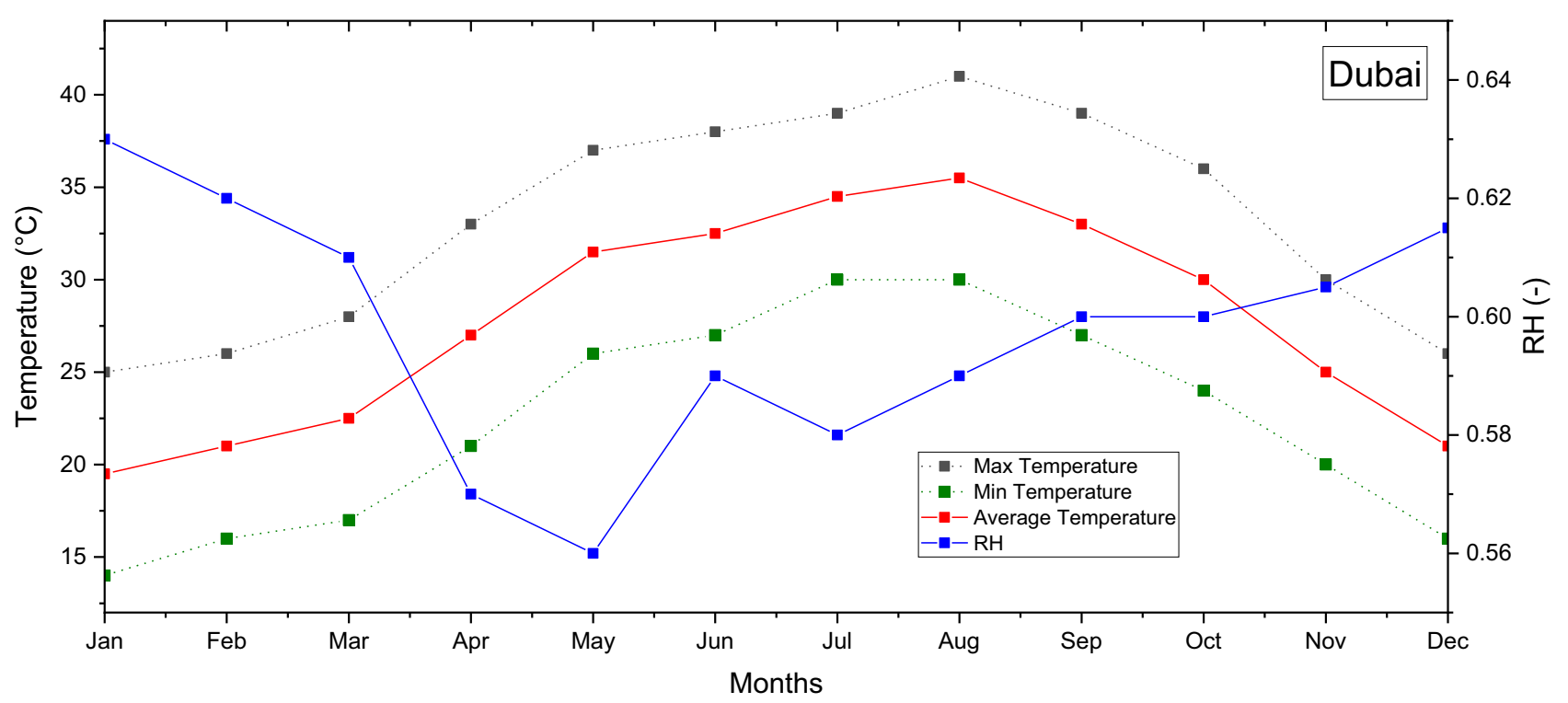

(b)

Fig. 8. Weather information; (a): Singapore; (b): Dubai.

$1 \mathrm{~h}$ during which the greater relative humidity causes the desiccant bed to reach its saturation level faster. This seriously obstructs the water absorption phenomena during the dehumidification process and eventually leads to the decrease in moisture extraction efficiency.

In Fig. 6(c), when solar intensity increases from $600 \mathrm{~W} / \mathrm{m}^{2}$ to $1800 \mathrm{~W} / \mathrm{m}^{2}$, the moisture removal efficiency increases from 0.32 to 0.74 whereas the dehumidification process remains constant. This trend was expected as in this particular case, temperature of the regeneration air was kept at $20^{\circ} \mathrm{C}$ and thus the solar radiation plays the key role in water evaporation phenomena during the regeneration process.

Fig. 6(d) illustrates the effect of regeneration temperature on system performance. An increase in regeneration temperature from $70{ }^{\circ} \mathrm{C}$ to $90^{\circ} \mathrm{C}$ leads to an increase in moisture removal efficiency from 0.83 to 0.98 . Whereas it does not have a significant effect on the dehumidification efficiency. The reason for this is that the solar radiation in this case was ignored and the warm regeneration air was the main factor in water evaporation phenomena. Thus temperature of the regeneration air directly influences the regeneration cycle as the greater regeneration temperature contributes to more heat and mass transfer from the saturated desiccant bed.

\subsubsection{Prediction of the system performance under randomly} generated operating conditions

In this section, sixteen conditions were generated randomly to simulate the performance of system. The moisture extraction and moisture removal efficiencies of the system were predicted by GPR model. The model was run for one hour of operation and the discrete values of the operating parameters that were used to generate the operating conditions are listed in Table 6 . As can be seen in Fig. $7(\mathrm{a})$, the moisture extraction efficiency was predicted to vary between 0.15 and 0.38 where the maximum and minimum levels occur in operating conditions 1 and 16 respectively. Comparing 


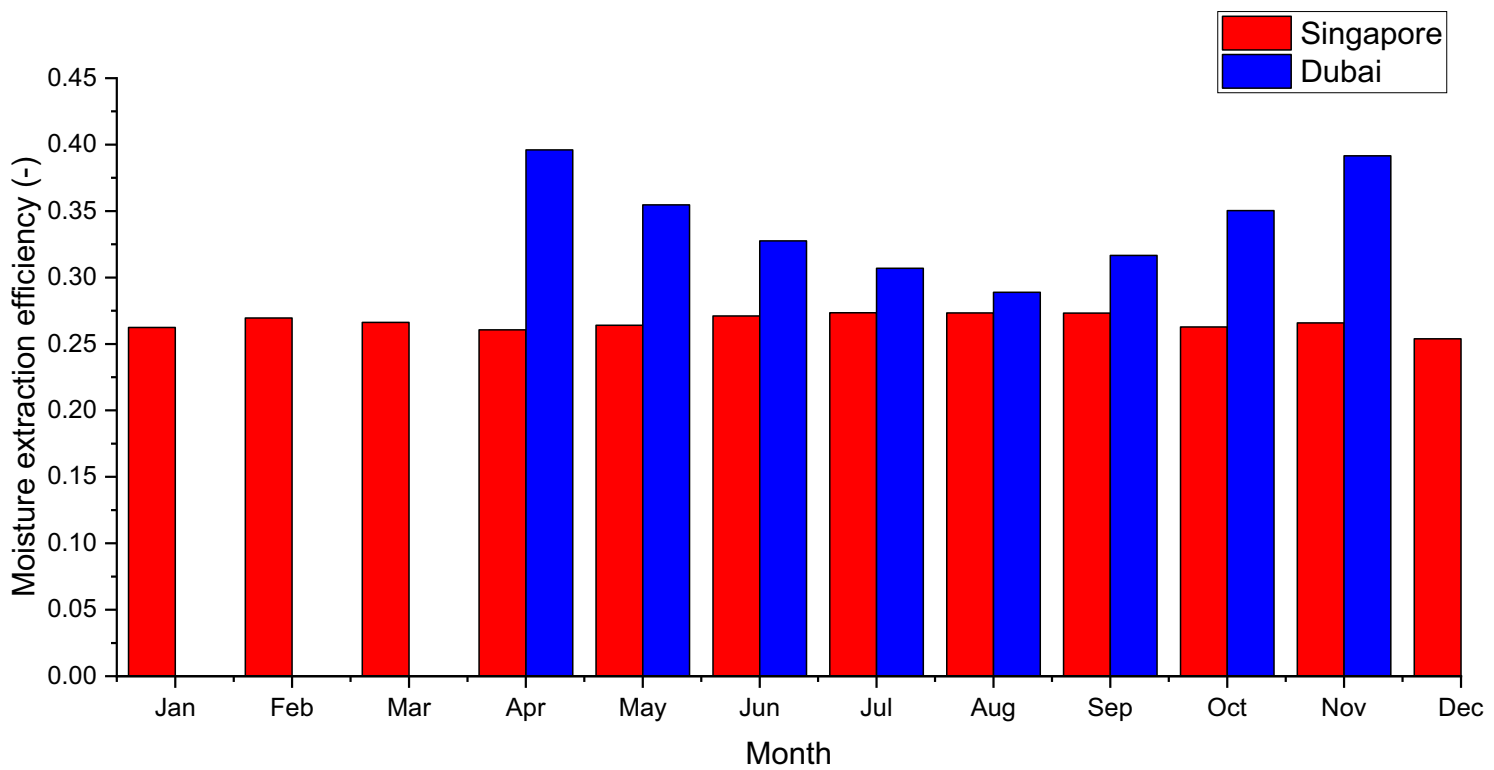

(a)

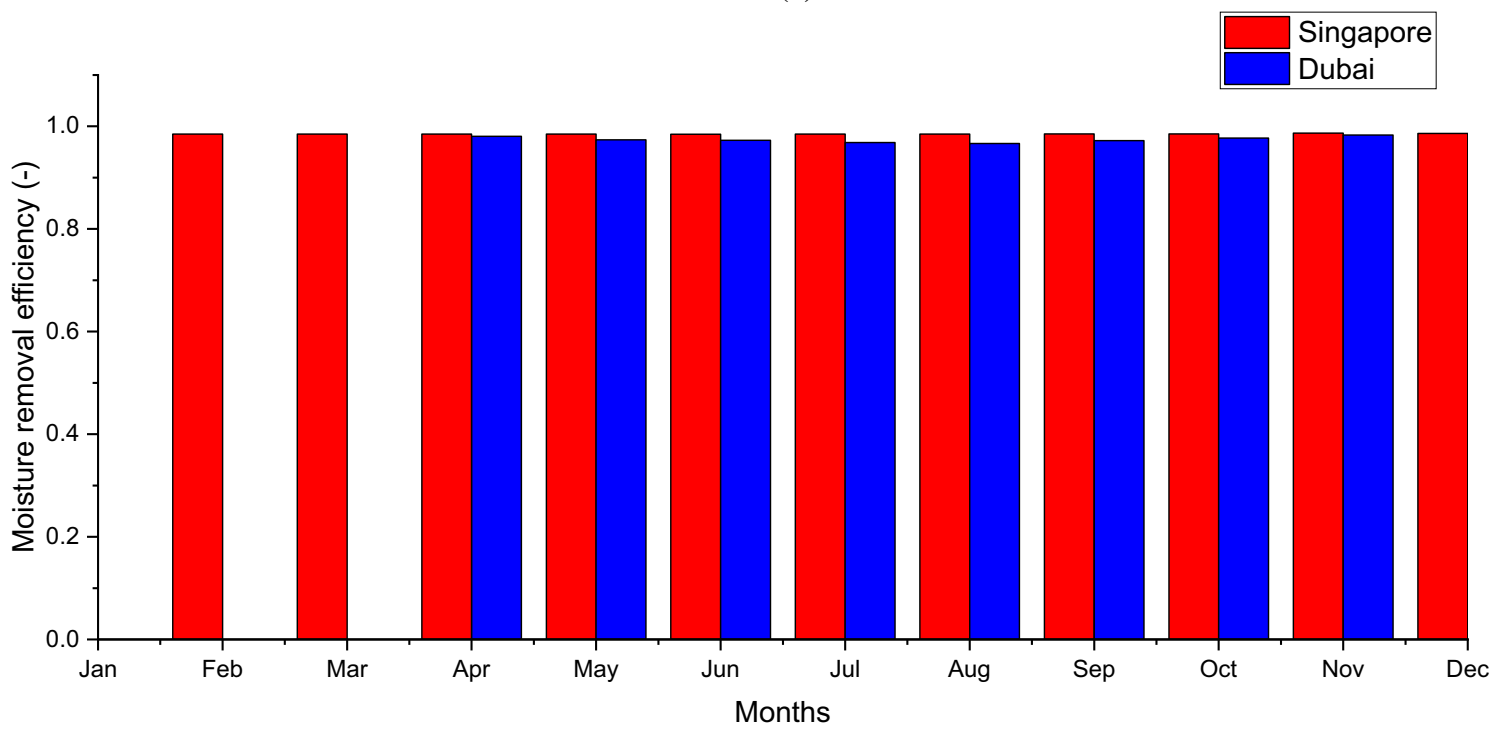

(b)

Fig. 9. Prediction of the system performance in warm and humid climate; (a): moisture extraction efficiency; (b): moisture removal efficiency.

Table 6

Randomly generated operating conditions.

\begin{tabular}{lllllll}
\hline $\mathrm{N}$ & $\mathrm{T}_{\mathrm{p}}\left[{ }^{\circ} \mathrm{C}\right]$ & $\mathrm{RH}_{\mathrm{p}}[-]$ & $\mathrm{T}_{\mathrm{r}}\left[{ }^{\circ} \mathrm{C}\right]$ & $\mathrm{U}[\mathrm{m} / \mathrm{s}]$ & $\mathrm{L}_{\mathrm{d}}[\mathrm{m}]$ & $\mathrm{I}\left[\mathrm{W} / \mathrm{m}^{2}\right]$ \\
\hline 1 & 25 & 0.6 & 20 & 1 & 1 & 600 \\
2 & 26 & 0.7 & 20 & 2 & 2 & 1200 \\
3 & 27 & 0.8 & 20 & 3 & 3 & 1800 \\
4 & 28 & 0.9 & 70 & 4 & 4 & 0 \\
5 & 29 & 0.6 & 80 & 1 & 5 & 0 \\
6 & 30 & 0.7 & 90 & 2 & 1 & 0 \\
7 & 31 & 0.8 & 20 & 3 & 2 & 1200 \\
8 & 32 & 0.9 & 20 & 4 & 3 & 1800 \\
9 & 33 & 0.6 & 20 & 1 & 4 & 600 \\
10 & 34 & 0.7 & 20 & 2 & 5 & 1200 \\
11 & 35 & 0.8 & 20 & 3 & 1 & 1800 \\
12 & 36 & 0.9 & 20 & 4 & 2 & 600 \\
13 & 37 & 0.6 & 20 & 1 & 3 & 1200 \\
14 & 38 & 0.7 & 20 & 2 & 4 & 1800 \\
15 & 39 & 0.8 & 20 & 3 & 5 & 600 \\
16 & 40 & 0.9 & 20 & 4 & 1 & 600 \\
\hline
\end{tabular}

these two conditions reveals that the first condition is drier than the 16th condition, which has the most humid conditions among the randomly generated operating conditions. This simply has led the system to reach its lowest moisture extraction efficiency. For the regeneration cycle, as can be seen from Fig. 7(b), the system shows the best performance in operating conditions $3,8,11$ and 14. The reason for this performance lies in the fact that in the above-mentioned conditions, the solar radiation has the highest allowable amount, $1800 \mathrm{~W} / \mathrm{m}$, which is the main parameter responsible for water evaporation. In contrary, the regeneration cycle has the lowest moisture removal efficiency in operating condition 1 . Similarly, solar radiation in this condition, which is $600 \mathrm{~W} / \mathrm{m}^{2}$, is also the main effective factor in regeneration cycle. Among conditions 4, 5 and 6, where warm air is responsible for the water evaporation from the saturated desiccant bed, the moisture removal efficiency increase from 0.87 in condition 4 to 0.98 in condition 6 . This trend was expected as the temperature of the regeneration air was increased from $70^{\circ} \mathrm{C}$ in condition 4 to $90^{\circ} \mathrm{C}$ in condition 6 . 


\subsubsection{Prediction of the system performance in warm and climate weather conditions}

The model is used to predict the performance of the system in warm and humid climates i.e. Singapore and Dubai and their weather information [35] are shown in Fig. 8. The average temperature and $\mathrm{RH}$ humidity are chosen as input conditions of the process air. Flow rate of process air is $1[\mathrm{~m} / \mathrm{s}$ ] and length of the desiccant bed is $1[\mathrm{~m}]$. The regeneration process is assumed to be done by warm air only where the temperature of regeneration air is $90\left[{ }^{\circ} \mathrm{C}\right]$ and thus the solar radiation intensity is ignored. Additionally, the prediction is done for $1 \mathrm{~h}$ of operating time for each cycle.

The prediction is done for an entire year in Singapore but for Dubai, the dehumidification system is needed from April to November. The reason for this is that the average temperature and relative humidity of the selected months should be within the predefined ranges in Table 1 . The prediction results for both moisture extraction and moisture removal efficiencies are shown in Fig. 9. As can be seen, the moisture extraction efficiency in Singapore ranges $0.25-0.27$. The reason for this stability is the stable weather conditions in Singapore all along the year where the average temperature ranges from 25 to $27.45\left[{ }^{\circ} \mathrm{C}\right]$ and the relative humidity is between 0.82 and 0.9. Similarly, the moisture removal efficiency in Singapore is relatively constant at 0.98 . This is again because of the stable inputs of regeneration air where the main impacting factor, the temperature of regeneration air, is constant at $90\left[{ }^{\circ} \mathrm{C}\right]$ and the solar intensity is ignored. However, for Dubai, the moisture extraction efficiency ranged from 0.28 in August to 0.4 in April and the moisture removal efficiency is between 0.96 in August and 0.99 in November. The reason for relatively similar moisture removal efficiencies in both cities lies in the fact that apart from the condition of the desiccant bed happened during the dehumidification cycle, the main effecting factor is the warm air temperature, which is constant.

\section{Conclusion}

The authors were pioneered in bringing the Gaussian process regression into investigation of the dehumidification systems. The GPR model was first trained by a training set and then tested with a numerical model through the testing set. Such kind of effort directly correlated the main operating parameters of the desiccant system with the performance parameters. The selected operating parameters were temperature, relative humidity and flow rate of process air, temperature of the regeneration air, length of the desiccant bed, solar radiation intensity and operating time of the system and the selected performance parameters were moisture extraction efficiency for the dehumidification cycle and moisture removal efficiency for the regeneration cycle. The model was tested by a numerical model and was evaluated by three common metrics. The maximum RSME and MAPE were 0.045 and 0.21 for moisture extraction, and 0.082 and 0.39 for moisture removal efficiencies, respectively; and the lowest ${ }^{2}$ was 0.97 . The developed GPR model was employed to study the effect of four operating parameters on performance of the system, prediction of the performance parameters under 16 randomly generated operating conditions and warm and humid climates. The presented GPR model is prompt and time efficient in performance prediction of the dehumidification systems and is needless of heat and mass transfer equations. The model can be used as a robust and reliable tool in design and optimization of the dehumidification systems.

\section{Declaration of Competing Interest}

We wish to confirm that there are no known conflicts of interest associated with this publication and there has been no signifi- cant financial support for this work that could have influenced its outcome.

\section{Acknowledgement}

The authors would acknowledge our sincere appreciation to the financial supports from the European Commission H2020 MSCA program (for the EU H2020-MSCA-RISE-2016-734340 DEW-COOL4-CDC project)

\section{References}

[1] L. Dai, Y. Yao, F. Jiang, X. Yang, X. Zhou, P. Xiong, Sorption and regeneration performance of novel solid desiccant based on PVA-LiCl electrospun nanofibrous membrane, Polym. Test 64 (2017) 242-249.

[2] Y. Bi, W. Yang, X. Zhao, Numerical investigation of a solar/waste energy driven sorption/desorption cycle employing a novel adsorbent bed, Energy 149 (2018) 84-97.

[3] M.R. Safizadeh, M.A. Wahed, C. Bongs, K. Zaw, A. Morgenstern, H.-M. Henning, J. Luther, Two-stage air-dehumidification system for the tropics-experimental and theoretical analysis of a lab system, Energy Procedia 48 (2014) 982-990.

[4] F. Xiao, G. Ge, X. Niu, Control performance of a dedicated outdoor air system adopting liquid desiccant dehumidification, Appl. Energy 88 (1) (2011) 143-149.

[5] F. Calise, M.D. d'Accadia, C. Roselli, M. Sasso, F. Tariello, Desiccant-based AHU interacting with a CPVT collector: simulation of energy and environmental performance, Solar Energy 103 (2014) 574-594.

[6] G. Ge, F. Xiao, X. Xu, Model-based optimal control of a dedicated outdoor air-chilled ceiling system using liquid desiccant and membrane-based total heat recovery, Appl. Energy 88 (11) (2011) 4180-4190.

[7] X. Chen, Y. Su, D. Aydin, H. Bai, H. Jarimi, X. Zhang, S. Riffat, Experimental investigation of a polymer hollow fiber integrated liquid desiccant dehumidification system with aqueous potassium formate solution, Appl. Therm. Eng. 142 (2018) 632-643.

[8] H.-J. Cho, S.-Y. Cheon, J.-W. Jeong, Experimental analysis of dehumidification performance of counter and cross-flow liquid desiccant dehumidifiers, Appl. Therm. Eng. 150 (2019) 210-223.

[9] H. Bai, J. Zhu, Z. Chen, L. Ma, R. Wang, T. Li, Performance testing of a cross-flow membrane-based liquid desiccant dehumidification system, Appl. Therm. Eng. 119 (2017) 119-131.

[10] W. Yang, W. Wang, Z. Ding, Z. Wang, X. Zhao, S. He, Performance study of a novel solar solid dehumidification/regeneration bed for use in buildings air conditioning systems, Energies 10 (9) (2017) 1335.

[11] B. Su, W. Han, J. Sui, H. Jin, Feasibility of a two-stage liquid desiccant dehumidification system driven by low-temperature heat and power, Appl. Therm. Eng. 128 (2018) 795-804.

[12] J.-Y. Park, H.-W. Dong, H.-J. Cho, J.-W. Jeong, Energy benefit of a cascade liquid desiccant dehumidification in a desiccant and evaporative cooling-assisted building air-conditioning system, Appl. Therm. Eng. 147 (2019) 291-301.

[13] Y. Guo, A. Al-Jubainawi, X. Peng, Modeling and the feasibility study of a hybrid electrodialysis and thermal regeneration method for LiCl liquid desiccant dehumidification, Appl. Energy 239 (2019) 1014-1036.

[14] X. Song, L. Zhang, X. Zhang, Analysis of the temperatures of heating and cooling sources and the air states in liquid desiccant dehumidification systems regenerated by return air, Energy 168 (2019) 651-661.

[15] A. Ali, K. Ishaque, A. Lashin, N. Al Arifi, Modeling of a liquid desiccant dehumidification system for close type greenhouse cultivation, Energy 118 (2017) 578-589.

[16] R.S. Das, S. Jain, Performance characteristics of cross-flow membrane contactors for liquid desiccant systems, Appl. Energy 141 (2015) 1-11.

[17] Y. Li, S. Liu, L. Shu, Wind turbine fault diagnosis based on Gaussian process classifiers applied to operational data, Renew. Energy 134 (2018) 357-366.

[18] M. Shepero, D. van der Meer, J. Munkhammar, J. Widén, Residential probabilistic load forecasting: A method using Gaussian process designed for electric load data, Appl. Energy 218 (2018) 159-172.

[19] J.M. Wang, D.J. Fleet, A. Hertzmann, Gaussian process dynamical models for human motion, IEEE Trans. Pattern Anal. Mach. Intell. 30 (2) (2008) 283-298.

[20] M.Y. Byron, J.P. Cunningham, G. Santhanam, S.I. Ryu, K.V. Shenoy, M. Sahani, Gaussian-process factor analysis for low-dimensional single-trial analysis of neural population activity, J Neurophysiol 102 (1) (2009) 614-635, doi:10.1152/jn.90941.2008

[21] P. Jylänki, J. Vanhatalo, A. Vehtari, Robust Gaussian process regression with a student- $t$ likelihood, J. Mach. Learn. Res. 12 (Nov) (2011) 3227-3257.

[22] F. Kang, S. Han, R. Salgado, J. Li, System probabilistic stability analysis of soil slopes using Gaussian process regression with Latin hypercube sampling, Comput. Geotechnics 63 (2015) 13-25.

[23] M. Pal, S. Deswal, Modeling pile capacity using Gaussian process regression, Comput. Geotechnics 37 (7-8) (2010) 942-947.

[24] M. Guermoui, K. Gairaa, A. Rabehi, D. Djafer, S. Benkaciali, Estimation of the daily global solar radiation based on the Gaussian process regression methodology in the Saharan climate, Eur. Phys. J. Plus 133 (6) (2018) 211.

[25] M. Guermoui, F. Melgani, C. Danilo, Multi-step ahead forecasting of daily global and direct solar radiation: a review and case study of Ghardaia region, J. Clean. Prod. 201 (2018) 716-734. 
[26] J.-Y. Park, D.-S. Yoon, S.-J. Lee, J.-W. Jeong, Empirical model for predicting the dehumidification effectiveness of a liquid desiccant system, Energy Build. 126 (2016) 447-454

[27] X. Ou, W. Cai, X. He, D. Zhai, X. Wang, Dynamic modeling and validation of a liquid desiccant cooling and dehumidification system, Energy Build. 163 (2018) 44-57.

[28] P. Gandhidasan, M. Mohandes, Artificial neural network analysis of liquid desiccant dehumidification system, Energy 36 (2) (2011) 1180-1186.

[29] D. Jani, M. Mishra, P. Sahoo, Performance prediction of rotary solid desiccant dehumidifier in hybrid air-conditioning system using artificial neural network, Appl. Therm. Eng. 98 (2016) 1091-1103.

[30] C.E. Rasmussen, Gaussian processes in machine learning, in: Advanced Lectures On Machine Learning, Springer, 2004, pp. 63-71.
[31] Y.G. Akhlaghi, X. Ma, X. Zhao, S. Shittu, J. Li, A statistical model for dew point air cooler based on the multiple polynomial regression approach, Energy 181 (2019) 868-881.

[32] O. Roustant, D. Ginsbourger, and Y. Deville, “DiceKriging, Diceoptim: Two R packages for the analysis of computer experiments by Kriging-based metamodeling and optimization," 2012.

[33] M. Moustapha, J.-M. Bourinet, B. Guillaume, B. Sudret, Comparative study of kriging and support vector regression for structural engineering applications, ASCE-ASME J. Risk Uncertainty Eng. Syst., Part A 4 (2) (2018) 04018005.

[34] J. Gummadi, "A comparison of various interpolation techniques for modeling and estimation of radon concentrations in Ohio," 2013.

[35] https://weather-and-climate.com. "Climate and average monthly weather in Singapore; Dubai." 